\title{
Synthesis and Characterization of Novel Organosoluble, Thermal Stable and Optically Active Polyesters Derived from 5-(2-Phthalimidiylpropanoylamino)isophthalic Acid
}

\author{
Shadpour MALLAKPOUR ${ }^{\dagger}$ and Zahra RAFIEE \\ Organic Polymer Chemistry Research Laboratory, Department of Chemistry, Isfahan University of Technology, \\ Isfahan, 84156-83111, IRAN
}

(Received May 30, 2007; Accepted August 11, 2007; Published October 2, 2007)

\begin{abstract}
A new aromatic diacid monomer containing pendent L-alaninephthalimide group was synthesized in three steps in high yield and purity. Several new, highly soluble and optically active aromatic polyesters containing phthalimide and flexible chiral groups were prepared with moderate molecular weights by direct polycondensation with tosyl chloride $(\mathrm{TsCl})$, pyridine (Py) and $N, N$-dimethylformamide (DMF) as condensing agent. The aim of this work was to obtain novel optically active polyesters that were more soluble in common organic solvents while maintaining the high thermal stability. All polymers derived from such a diacid and aromatic diols were highly organosoluble in the solvents like $N$-methyl-2-pyrrolidinone, $N, N$-dimethylacetamide, DMF, Py and dimethyl sulfoxide. These new optically active polyesters with inherent viscosities ranging from 0.21 to $0.81 \mathrm{dL} / \mathrm{g}$ were obtained with high yields. Thermogravimetric analysis (TGA) data showed that these polyesters are thermal stable, with $10 \%$ weight loss being recorded above $370{ }^{\circ} \mathrm{C}$. Some of the above polymers were characterized by ${ }^{1} \mathrm{H}-\mathrm{NMR}$, FT-IR, elemental analyses and specific rotation techniques. [doi:10.1295/polymj.PJ2007061]

KEY WORDS Polyester / Optically Active Polymers / TsCl/Py/DMF Condensing Agent / Thermal Properties / Solubility / Direct Polycondensation /
\end{abstract}

Polyesters (PE)s are significant class of high performance and engineering macromolecules, which find utilize in a number of various applications. ${ }^{1-3}$ They are typically prepared by the solution or interfacial polymerization reaction between dicarboxylicacid chlorides and diols, ${ }^{4,5}$ and an acid or phenyl ester exchange reaction of the acetate or ester of the acids under severe conditions (high temperature and reduced pressure). Thermally stable PEs derived from isophthalic and terephthalic acids with bisphenol-A have been commercialized. ${ }^{6}$ However, PEs are generally difficult to process because of their limited solubility in many organic solvents and their high melting temperature or high glass-transition temperature due to their rigid structures. Hence, expansion of PEs for use at high temperature with better solubility is an important ambition.

One of the approaches to improve solubility of the macromolecules without excessive loss of their high thermal stability is the introduction of flexible and bulky groups into the polymer backbone. ${ }^{7-10}$ The amalgamation of bulky pendent groups can also supply beneficial effect for solubility because this approach generates a separation of chains and lowering the chain packing with a gain of free volumes.

Numerous condensing agents appropriate for the direct polycondensation reaction have been developed. ${ }^{11,12}$ On the other hand, it was established that
Vilsmeier adduct derived from arylsulfonyl chlorides and $N, N$-dimethylformamide (DMF) in pyridine (Py) was effectively used as a proper condensing agent for the preparation of aromatic PEs by the direct polycondensation of hydroxybenzoic acids and also aromatic dicarboxylic acids with bisphenols. ${ }^{13,14}$

The synthesis and properties of novel chiral polymers is of special attention from the point of view of material science, since a high degree of amino acid functionality and chirality can lead to polymers with enhanced solubility and the ability to form regulated higher order structures. ${ }^{15-17}$ Chirality is a major disquiet in the modern pharmaceutical industry. This curiosity can be ascribed largely to a heightened consciousness that enantiomers of a racemic drug may have diverse pharmacological activities, as well as different pharmacokinetic and pharmacodynamic outcomes. The severance of chiral compounds has been of great attention because the majority of bioorganic molecules are chiral. Recent progresses in asymmetric reactions and catalysis as well as in chiral separations have gave a rapid enhance in the number of commercially available optically active compounds and reagents. ${ }^{18,19}$ This circumstance will influence new methodologies for the synthesis of optically active polymers (OAPs) in the coming century. So far, chiral macromolecules have found flourishing applications in chiral chromatographic separations and shown po-

${ }^{\dagger}$ To whom correspondence should be addressed (Tel: +98-311-391-3267, Fax: +98-311-391-2350, E-mail: mallak@cc.iut.ac.ir). 
tential uses in chiral catalytic systems, liquid crystals, optical switches, biomedical devices, etc. A direct and efficient approach for synthesizing chiral polymers is to introduce chiral elements into the macromolecule backbone or the side chains. ${ }^{20}$ We now have a diversity of utensil for the synthesis of novel chiral monomers and polymers. Recently, we have synthesized a variety of OAPs by different methods, such as modification of polybutadiene with an optically active substituted urazole group, Diels-Alder-Ene reactions, and the reaction of an optically active monomer with a number of diamines via solution polymerization. ${ }^{21-23}$ In the last case, we use amino acids as a chiral agent in the backbone of the macromolecules. Because the amino acids are naturally occurring compounds, synthetic polymers based on amino acids are anticipated to be nontoxic, biocompatible, and biodegradable. On the other hand, synthetic polymers containing amino acid residues in the main chain or in the side chain can be employed for biomedical applications.

In continuation of our study to develop new OAPs via direct polycondnsation, ${ }^{21-26}$ in this investigation, we describe the successful synthesis and characterization of new optically active PEs containing chiral Lalanine and thermal stable phthalimide moieties using tosyl chloride ( $\mathrm{TsCl}) / \mathrm{DMF} / \mathrm{Py}$ as condensing agent. Furthermore, the resulting polymers due to the presence of phthalimide moieties exhibit a number of applications in biology ${ }^{27}$ and owing to the presence of amino acid moiety are expected to be biodegradable and biocompatible.

\section{EXPERIMENTAL}

\section{Materials}

All chemicals were purchased from Fluka Chemical Co. (Buchs, Switzerland), Aldrich Chemical Co. (Milwaukee, WI), Riedel-deHaen AG (Seelze, Germany) and Merck Chemical Co.). 5-Aminoisophthalic acid was recrystallized from a mixture of DMF/water (v/v ratio 3:1). Bisphenol A (6a) was purified by recrystallization from acetic acid-water. The other diols were used as obtained without further purification. $N, N$-dimethylacetamide (DMAc) and DMF were dried over $\mathrm{BaO}$ and then were distilled under reduced pressure.

\section{Measurements}

Proton nuclear magnetic resonance $\left({ }^{1} \mathrm{H}\right.$ NMR, $500 \mathrm{MHz})$ and ${ }^{13} \mathrm{C}$ NMR $(125 \mathrm{MHz})$ spectra were recorded on a Bruker (Germany) Avance 500 instrument. FT-IR spectra were recorded on (Jasco-680, Japan) spectrophotometer. The spectra of solids were obtained using $\mathrm{KBr}$ pellets. The vibrational transition frequencies are reported in wave numbers $\left(\mathrm{cm}^{-1}\right)$.
Band intensities are assigned as weak (w), medium (m), shoulder (sh), strong (s) and broad (br). Inherent viscosities were measured by a standard procedure using a Cannon Fensk routine viscometer. Specific Rotations were measured by a Jasco Polarimeter (Japan), with a concentration of $0.5 \mathrm{~g} / \mathrm{dL}$ in DMF solution under sodium lamp with a wavelength of $589 \mathrm{~nm}$, mercury lamp without a filter and mercury lamp with a filter (wavelength of $365 \mathrm{~nm}$ ), respectively. Thermal gravimetric analysis (TGA) data for polymers were taken on TGA-PerkinElmer (Pyris 1) in nitrogen atmosphere at a rate heating of $10^{\circ} \mathrm{C} / \mathrm{min}$. Elemental analyses were performed by the Iran Polymer and Petrochemical Research Institute (IPPI), Tehran, Iran. DSC data were recorded on a DSCPL-1200 instrument under $\mathrm{N}_{2}$ atmosphere also by IPPI. Glass transition temperatures $(\mathrm{Tg})$ were read at the middle of the transition in the heat capacity taken from the heating DSC traces.

\section{Monomer synthesis}

$N$-Phthalimidiylpropanoic acid (3). Into a $100 \mathrm{~mL}$ round-bottomed flask $3.00 \mathrm{~g}\left(1.66 \times 10^{-2} \mathrm{~mol}\right)$ of phthalic anhydride $(\mathbf{1}), 1.47 \mathrm{~g}\left(1.66 \times 10^{-2} \mathrm{~mol}\right)$ of L-alanine (2), $20 \mathrm{~mL}$ of acetic acid and stirring bar were placed. The mixture was refluxed for $12 \mathrm{~h}$. The solvent was removed under reduced pressure and to the residue mixture of $100 \mathrm{~mL} / 5 \mathrm{~mL}$ cold water/concentrated $\mathrm{HCl}$ was added. A white precipitate was formed, filtered off, washed several times with water and dried, to give $3.47 \mathrm{~g}(96 \%)$ of imide acid 3. Recrystallization from methanol/water gave white crystals, mp $142-143^{\circ} \mathrm{C}$; Lit: $\mathrm{mp} 145-147^{\circ} \mathrm{C},{ }^{28}[\alpha]_{\mathrm{D}}^{25}=$ -48.8 (0.05 g in $10 \mathrm{~mL}$ DMF); FT-IR (KBr): 3257 (s, br), 2998 (m), 2950 (m), 2919 (m), 1757 (s), 1692 (s), 1609 (m), $1465(\mathrm{~m}), 1445$ (m), 1402 (s), $1344(\mathrm{~s}), 1288(\mathrm{~m}), 1210(\mathrm{~s}), 1197$ (s), 1170 (s), 1147 (s), 1072 (s), 1022 (s), 1008 (m), 967 (m), 915 (m), 883 (s), $818(\mathrm{~m}), 799(\mathrm{~m}), 757$ (s), $741(\mathrm{~s}), 724$ (s), $625(\mathrm{~s}), 571(\mathrm{~m}), 550(\mathrm{~m}), 530(\mathrm{~s}) \mathrm{cm}^{-1}$.

$\mathrm{N}$-Phthalimidiylpropanoyl chloride (4). Into a $50 \mathrm{~mL}$, a round-bottom flask, $1.00 \mathrm{~g}\left(4.56 \times 10^{-3}\right)$ of imide acid 3,10 $\mathrm{mL}$ (an excess amount) of thionyl chloride, and stirring bar were placed. The stirrer was started and the mixture was refluxed for $6 \mathrm{~h}$. The thionyl chloride was removed via distillation, $20 \mathrm{~mL}$ of $n$-hexane was added, the mixture was stirred for $1 \mathrm{~h}, n$-hexane was distilled off, and the solid was collected and dried in vacuum to give $1.02 \mathrm{~g}(94 \%)$ of a white solid, mp $62-63^{\circ} \mathrm{C},[\alpha]_{\mathrm{D}}^{25}=-50.3(0.05 \mathrm{~g}$ in $10 \mathrm{~mL}$ DMF); FT-IR (KBr): $2950(\mathrm{~m}), 1790(\mathrm{~s})$, 1720 (s), 1630 (m), 1460 (m), 1380 (s), 1260 (m), $1230(\mathrm{~m}), 1190(\mathrm{~m}), 1160(\mathrm{~m}), 1080(\mathrm{~m}), 1050(\mathrm{~m})$, $992(\mathrm{~m}), 940(\mathrm{~m}), 870(\mathrm{~m}), 830(\mathrm{~m}), 790(\mathrm{~m}), 765$ (m), $720(\mathrm{~s}), 640(\mathrm{w}), 600(\mathrm{w}) \mathrm{cm}^{-1} \cdot{ }^{1} \mathrm{H}-\mathrm{NMR}(500$ 
$\left.\mathrm{MHz}, \mathrm{CDCl}_{3}\right): \delta 1.82-1.84(\mathrm{~d}, 3 \mathrm{H}, J=7.2 \mathrm{~Hz}), 5.19-$ $5.23(\mathrm{q}, 1 \mathrm{H}, J=7.2 \mathrm{~Hz}), 7.83-7.85(\mathrm{~m}, 2 \mathrm{H}, \operatorname{Ar}-\mathrm{H})$, 7.94-7.97 (m, 2H, Ar-H) ppm; ${ }^{13} \mathrm{C}$ NMR $(125 \mathrm{MHz}$, $\left.\mathrm{CDCl}_{3}\right): \delta 15.88,56.39,124.33,132.05,135.05$, $167.12,172.47 \mathrm{ppm}$.

5-(2-Phthalimidiylpropanoylamino)isophthalic acid (5). Into a $25 \mathrm{~mL}$ round-bottomed flask fitted with a magnetic stirrer was placed a solution of $0.76 \mathrm{~g}$ $\left(4.21 \times 10^{-3} \mathrm{~mol}\right)$ of 5 -aminoisophthalic acid in $3 \mathrm{~mL}$ of DMAc. The reaction mixture was cooled in an ice water bath. To this solution $1.00 \mathrm{~g}\left(4.21 \times 10^{-3} \mathrm{~mol}\right)$ of acid chloride 4 in $2 \mathrm{~mL}$ of DMAc was added dropwise. The mixture was stirred in ice bath for $3 \mathrm{~h}$, then $0.58 \mathrm{~mL}\left(4.21 \times 10^{-3} \mathrm{~mol}\right)$ of triethylamine was added. The resulting mixture was stirred vigorously for $2 \mathrm{~h}$ in ice bath and then for an overnight at room temperature. Finally it was refluxed for $30 \mathrm{~min}$., then the mixture was poured into $100 \mathrm{~mL} / 5 \mathrm{~mL}$ of cold water/concentrated $\mathrm{HCl}$. The precipitate was collected by filtration and washed thoroughly with water and dried at $70^{\circ} \mathrm{C}$ for $7 \mathrm{~h}$, to yield $1.33 \mathrm{~g}(83 \%)$ of diacid 5. Recrystallization from ethanol/water gave white crystals, $\mathrm{mp} 285-286^{\circ} \mathrm{C},[\alpha]_{\mathrm{D}}^{25}=-32.5(0.050 \mathrm{~g}$ in $10 \mathrm{~mL}$ DMF); FT-IR (KBr): 3330 (m), 2963 (m, br), 1775 (m), 1700 (s, br), 1605 (s), 1540 (s), 1445 (s), 1392 (s), 1260 (m), 1208 (s), 1170 (m), 1150 (m), 1080 (m), 1016 (m), 940 (m), 908 (m), 880 (m), 850 (m), $760(\mathrm{~m}), 720(\mathrm{~m}), 650(\mathrm{~m}) \mathrm{cm}^{-1} \cdot{ }^{1} \mathrm{H}-\mathrm{NMR}$ $\left(500 \mathrm{MHz}\right.$, DMSO- $\left.d_{6}\right): \delta 1.58-1.59(\mathrm{~d}, 3 \mathrm{H}, J=7.3$ $\mathrm{Hz}), 4.97-5.00(\mathrm{q}, 1 \mathrm{H}, J=7.1 \mathrm{~Hz}), 7.87-7.89(\mathrm{~m}$, 2H, Ar-H), 7.92-7.94 (m, 2H, Ar-H), $8.17(\mathrm{~s}, 1 \mathrm{H}$, Ar-H), 8.43 (s, 2H, Ar-H), 10.21 (s, 1H, N-H), 13.27 (s, 2H, COOH) ppm; ${ }^{13} \mathrm{C} \mathrm{NMR}(125 \mathrm{MHz}$, DMSO- $\left.d_{6}\right): \delta 15.86,49.44,124.05,125.21,125.72$, $132.50,132.70,135.39,140.22,167.27,168.22$, 168.97 ppm. Elemental analysis: Calcd. for $\mathrm{C}_{19} \mathrm{H}_{14}$ $\mathrm{N}_{2} \mathrm{O}_{7}: \mathrm{C}, 59.69 \% ; \mathrm{H}, 3.69 \%$;, $7.33 \%$. Found: $\mathrm{C}$, $59.07 \%$; H, 3.24\%; N, $7.01 \%$.

\section{Polymer synthesis}

All of the polymers were synthesized using two different methods: For synthesis of PE7a.

Method I: A Py $\left(0.15 \mathrm{~mL}, 1.9 \times 10^{-3} \mathrm{~mol}\right)$ solution of $\mathrm{TsCl}\left(0.257 \mathrm{~g}, 1.3 \times 10^{-3} \mathrm{~mol}\right)$ after $30 \mathrm{~min}$. stirring at room temperature, was treated with DMF $\left(0.10 \mathrm{~mL}, 1.3 \times 10^{-3} \mathrm{~mol}\right)$ for $30 \mathrm{~min}$. and was added dropwise to a solution of diacid $5\left(0.100 \mathrm{~g}, 2.6 \times 10^{-4}\right.$ $\mathrm{mol})$ in Py $(0.15 \mathrm{~mL})$. The mixture was maintained at room temperature for $30 \mathrm{~min}$. and then to this mixture, a solution of bisphenol A (6a) $\left(0.060 \mathrm{~g}, 2.6 \times 10^{-4}\right.$ $\mathrm{mol})$ in Py $(0.15 \mathrm{~mL})$ was added dropwise at room temperature and the whole solution was stirred at room temperature for $30 \mathrm{~min}$. and at $120^{\circ} \mathrm{C}$ for $5 \mathrm{~h}$. As the reaction ensue, the solution became viscous. Then the viscous liquid was precipitated in $30 \mathrm{~mL}$ of methanol to yield $0.137 \mathrm{~g}(86 \%)$ of the PE7aI.

Method II: A Py $\left(0.15 \mathrm{~mL}, 1.9 \times 10^{-3} \mathrm{~mol}\right)$ solution of $\mathrm{TsCl}\left(0.257 \mathrm{~g}, 1.3 \times 10^{-3} \mathrm{~mol}\right)$ after $30 \mathrm{~min}$. stirring at room temperature, was treated with DMF $\left(0.10 \mathrm{~mL}, 1.3 \times 10^{-3} \mathrm{~mol}\right)$ for $30 \mathrm{~min}$. and the solution was added dropwise to a solution of diacid $\mathbf{5}$ $\left(0.100 \mathrm{~g}, 2.6 \times 10^{-4} \mathrm{~mol}\right)$ in Py $(0.15 \mathrm{~mL})$. The mixture was maintained at room temperature for $30 \mathrm{~min}$. and at $120^{\circ} \mathrm{C}$ for $1 \mathrm{~h}$. Then to this mixture, a solution of diol $6 \mathbf{6 a}\left(0.060 \mathrm{~g}, 2.6 \times 10^{-4} \mathrm{~mol}\right)$ in Py $(0.15 \mathrm{~mL})$ was added dropwise at room temperature and the whole solution was stirred at room temperature for $30 \mathrm{~min}$. and at $120^{\circ} \mathrm{C}$ for $2.5 \mathrm{~h}$. As the reaction proceeded, the solution became viscous. Then the viscous liquid was precipitated in $30 \mathrm{~mL}$ methanol to yield $0.131 \mathrm{~g}(82 \%)$ of the PE7aII.

FT-IR (KBr): 3362 (m), $3102(\mathrm{w}), 2968$ (m), 1780 (m), 1717 (s), 1604 (m), 1547 (m), 1504 (m), 1452 (m), 1426 (s), 1385 (s), 1337 (s), 1200 (s), 1170 (s), $1097(\mathrm{~m}), 1078(\mathrm{~m}), 1016(\mathrm{~m}), 943(\mathrm{w}), 915(\mathrm{w})$, $878(\mathrm{w}), 853(\mathrm{w}), 818(\mathrm{w}), 748(\mathrm{~m}), 720(\mathrm{~m}) \mathrm{cm}^{-1}$, ${ }^{1} \mathrm{H}-\mathrm{NMR}\left(500 \mathrm{MHz}, \mathrm{DMSO}-d_{6}\right): \delta 1.61(\mathrm{~s}, \mathrm{br}, 9 \mathrm{H}$, $\mathrm{CH}_{3}$ ), 4.97 (s, br, $\left.1 \mathrm{H}, \mathrm{CH}\right), 7.20-7.30(\mathrm{~m}, \mathrm{br}, 8 \mathrm{H}$, Ar-H), 7.86-7.90 (m, br, 4H, Ar-H), $8.43(\mathrm{~s}, 1 \mathrm{H}$, Ar-H), 8.68 (s, 1H, Ar-H), 10.43 (s, 1H, N-H) ppm. Elemental analysis: calcd for $\mathrm{C}_{34} \mathrm{H}_{26} \mathrm{~N}_{2} \mathrm{O}_{7}: \mathrm{C}$, 71.07\%; H, 4.56\%; N, 4.87\%. Found: C, 69.58\%; H, $4.44 \%$; N, $4.75 \%$.

The other PEs, $\mathbf{7 b}-\mathbf{7 j}$ were prepared with similar procedures.

PE7b

FT-IR (KBr): 3412 (m), 3095 (w), 1779 (w), 1741 (s), 1715 (s), 1607 (m), 1547 (m), 1487 (s), 1451 (w), $1425(\mathrm{w}), 1386(\mathrm{~s}), 1336(\mathrm{~m}), 1265(\mathrm{w}), 1194$ (s), 1163 (s), $1080(\mathrm{~m}), 1013(\mathrm{~m}), 945(\mathrm{w}), 914(\mathrm{w})$, $879(\mathrm{w}), 848(\mathrm{w}), 810(\mathrm{w}), 746(\mathrm{w}), 721(\mathrm{~m}) \mathrm{cm}^{-1}$, ${ }^{1} \mathrm{H}-\mathrm{NMR}\left(500 \mathrm{MHz}\right.$, DMSO- $\left.d_{6}\right): \delta 1.63\left(\mathrm{~d}, 3 \mathrm{H}, \mathrm{CH}_{3}\right)$, 4.97 (s, br, 1H, CH), 7.22-7.34 (m, br, 8H, Ar-H), 7.83-7.86 (m, br, 4H, Ar-H), $8.32(\mathrm{~s}, 1 \mathrm{H}, \operatorname{Ar}-\mathrm{H})$, 8.59 (s, 1H, Ar-H), 10.38 (s, 1H, N-H) ppm.

\section{PE7c}

FT-IR (KBr): 3413 (m), 3092 (w), 2965 (w), 1778 (w, sh), 1744 (m), 1715 (s), 1637 (m), 1603 (m), 1552 (m), 1507 (m), 1452 (m), $1386(\mathrm{~m}), 1337$ (m), 1197 (s), $1162(\mathrm{~m}), 1099(\mathrm{~m}), 960(\mathrm{w}), 881(\mathrm{w}), 784(\mathrm{w})$, $745(\mathrm{w}), 721(\mathrm{w}) \mathrm{cm}^{-1}$.

\section{PE7d}

FT-IR (KBr): 3411 (m), 3067 (w), 2966 (w), 1779 (m), 1745 (s), $1716(\mathrm{~s}), 1607$ (m), 1548 (m), 1467 (m), 1423 (s), 1385 (s), 1337 (s), $1200(\mathrm{w}), 1160$ (w), 1095 (w), $880(\mathrm{w}), 795(\mathrm{w}), 746(\mathrm{w}), 720(\mathrm{~m}) \mathrm{cm}^{-1}$.

\section{PE7e}

FT-IR (KBr): 3413 (w), 3077 (w), 2941 (w), 1779 (w), $1742(\mathrm{~s}), 1714$ (s), $1603(\mathrm{~m}), 1553(\mathrm{~m}), 1499$ (s), 1453 (w), 1425 (w), 1386 (s), 1339 (s), 1211 (s), 1170 
(s), $1097(\mathrm{~m}), 1034(\mathrm{w}), 1013(\mathrm{w}), 947(\mathrm{w}), 915(\mathrm{w})$, $879(\mathrm{w}), 817(\mathrm{w}), 796(\mathrm{w}), 747(\mathrm{w}), 721(\mathrm{~m}) \mathrm{cm}^{-1}$.

\section{PE7f}

FT-IR (KBr): 3413 (m), 3075 (w), 2965 (w), 1777 (m), $1746(\mathrm{~s}), 1715(\mathrm{~s}), 1637(\mathrm{~m}), 1612(\mathrm{~m}), 1547(\mathrm{~m})$, $1505(\mathrm{~m}), 1466(\mathrm{~m}), 1386(\mathrm{~m}), 1337(\mathrm{~m}), 1288(\mathrm{~m})$, 1197 (s), 1168 (s), 1102 (m), $1084(\mathrm{~m}), 1017$ (w), $972(\mathrm{w}), 930(\mathrm{w}), 878(\mathrm{w}), 797(\mathrm{w}), 746(\mathrm{~m}), 721(\mathrm{~m})$ $\mathrm{cm}^{-1}$. Elemental analysis: calcd for $\mathrm{C}_{39} \mathrm{H}_{24} \mathrm{~N}_{2} \mathrm{O}_{9}$ : C, $70.48 \%$; H, 3.64\%; N, 4.21\%. Found: C, 69.36\%; H, $3.56 \% ; \mathrm{N}, 4.55 \%$.

\section{PE7g}

FT-IR (KBr): 3435 (m), 3089 (w), 2928 (w), 1779 (m), 1716 (s), 1598 (s), 1527 (s, sh), 1473 (w), 1437 (w), 1407 (m), $1383(\mathrm{~m}), 1318(\mathrm{~m}), 1261$ (s, sh), 1195 (s), 1173 (s), 1102 (w, sh), 1068 (m), 1009 (m), 854 (w), 760 (m), $726(\mathrm{~m}), 691(\mathrm{~m}) \mathrm{cm}^{-1}$.

\section{PE7h}

FT-IR (KBr): 3412 (m), 3085 (w), 2975 (w), 1778 (m), 1747 (s), 1715 (s), 1606 (s), 1552 (m), 1493 (w), $1451(\mathrm{~m}), 1425(\mathrm{w}), 1386(\mathrm{~s}), 1337(\mathrm{~m}), 1250(\mathrm{~m})$, 1199 (s), 1153 (m), 1125 (m), 1091 (m), 1019 (w), $985(\mathrm{w}), 906(\mathrm{w}), 879(\mathrm{w}), 745(\mathrm{w}), 722(\mathrm{~m}) \mathrm{cm}^{-1}$.

\section{PE7i}

FT-IR (KBr): 3413 (s), 3076 (w), 2965 (w), 1749 (m), $1714(\mathrm{~s}), 1673(\mathrm{~s}), 1637$ (m), $1616(\mathrm{~m}), 1589(\mathrm{~m})$, $1552(\mathrm{~m}), 1488(\mathrm{w}), 1452(\mathrm{~m}), 1386(\mathrm{~s}), 1338(\mathrm{~m})$, $1263(\mathrm{~m}), 1185$ (s), 1168 (s), 1092 (m), 1033 (w), 1009 (w), $951(\mathrm{w}), 876(\mathrm{w}), 798(\mathrm{w}), 721(\mathrm{~m}) \mathrm{cm}^{-1}$. PE7j

FT-IR (KBr): 3413 (s), 2980 (w), 1779 (w), 1744 (m), $1715(\mathrm{~s}), 1602(\mathrm{~m}), 1559(\mathrm{~m}), 1507(\mathrm{~m}), 1452$ (m), 1385 (s), 1338 (m), 1197 (s), 1162 (s), 1099 (m), $961(\mathrm{w}), 784(\mathrm{w}), 745(\mathrm{w}), 721(\mathrm{w}) \mathrm{cm}^{-1}$.

\section{RESULTS AND DISCUSSIONS}

\section{Monomer synthesis}

As shown in Scheme 1, the novel monomer 5-(2phthalimidiylpropanoylamino)-isophthalic acid (5) was synthesized by a three-step route. In the first step the reaction of L-alanine with phthalic anhydride in acetic acid afforded the $N$-phthalimidiylpropanoic acid (3). The acid chloride 4 was obtained in high yield by treatment of corresponding carboxylic acid with excess thionyl chloride, which was subsequently reacted with 5-aminoisophthalic acid in the presence of triethylamine in a typical low-temperature condensation reaction. The reaction was performed in dry DMAc due to partial solubility of 5-aminoisophthalic acid.

The chemical structure and purity of the optically active acid chloride $\mathbf{4}$ and diacid 5 were proven with FT-IR, ${ }^{1} \mathrm{H}-\mathrm{NMR}$ and ${ }^{13} \mathrm{C}$-NMR spectroscopic techniques. The ${ }^{1} \mathrm{H}-\mathrm{NMR}$ spectrum $(500 \mathrm{MHz})$ of com-
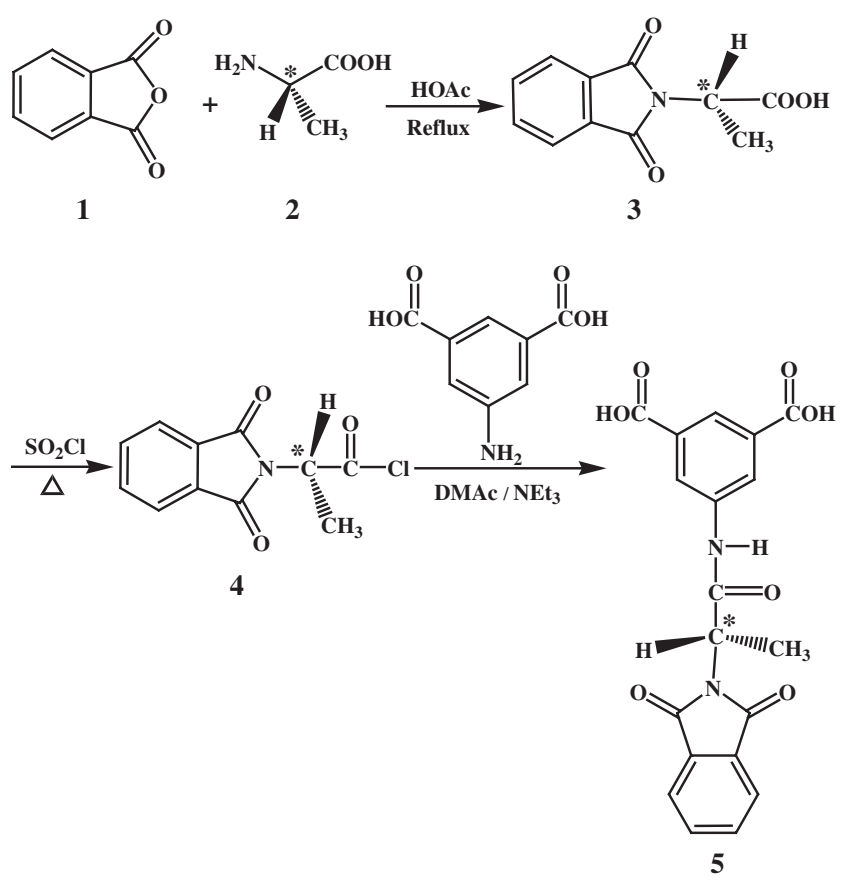

Scheme 1. Synthesis of monomer 5.

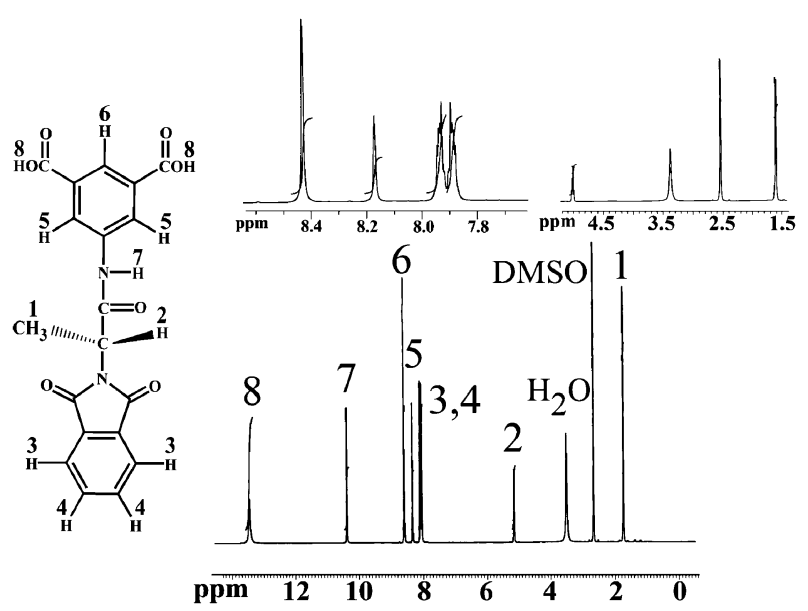

Figure 1. ${ }^{1} \mathrm{H}-\mathrm{NMR}(500 \mathrm{MHz})$ spectrum of monomer 5.

pound $\mathbf{5}$ is shown in Figure 1. The ${ }^{1} \mathrm{H}$ NMR of this diacid shows the characteristic absorption of $\mathrm{C}-\mathrm{H}$ chiral center (quartet), $\mathrm{N}-\mathrm{H}$ amide group and acidic $\mathrm{O}-\mathrm{H}$ at $4.98,10.21$ and $13.27 \mathrm{ppm}$, respectively. Figure 2 shows ${ }^{13} \mathrm{C}-\mathrm{NMR}$ spectrum $(125 \mathrm{MHz})$ of monomer 5. The results of elemental analysis of diacid $\mathbf{5}$ are in good agreement with the calculated values.

\section{Polymer synthesis}

PEs 7a-7j were synthesized by the direct polycondensation of diacid $\mathbf{5}$ and various aromatic diols 6a-6j utilizing $\mathrm{TsCl} / \mathrm{Py} / \mathrm{DMF}$ as condensing agent (Scheme 2).

The polymerization of diacid $\mathbf{5}$ with aromatic diols $\mathbf{6 a - 6 j}$ was performed under two different methods. In method $\mathbf{I}$, the polycondensation was carried out in the 


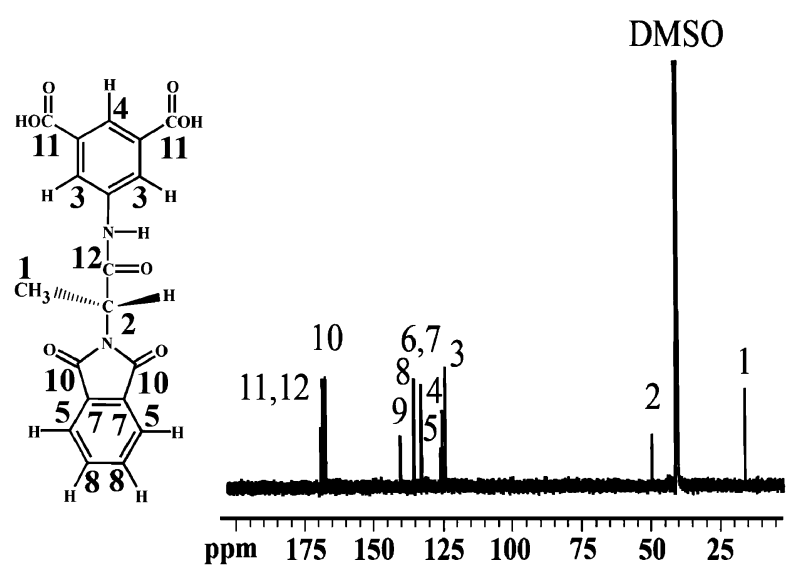

Figure 2. ${ }^{13} \mathrm{C}-\mathrm{NMR}(125 \mathrm{MHz})$ spectrum of monomer 5.

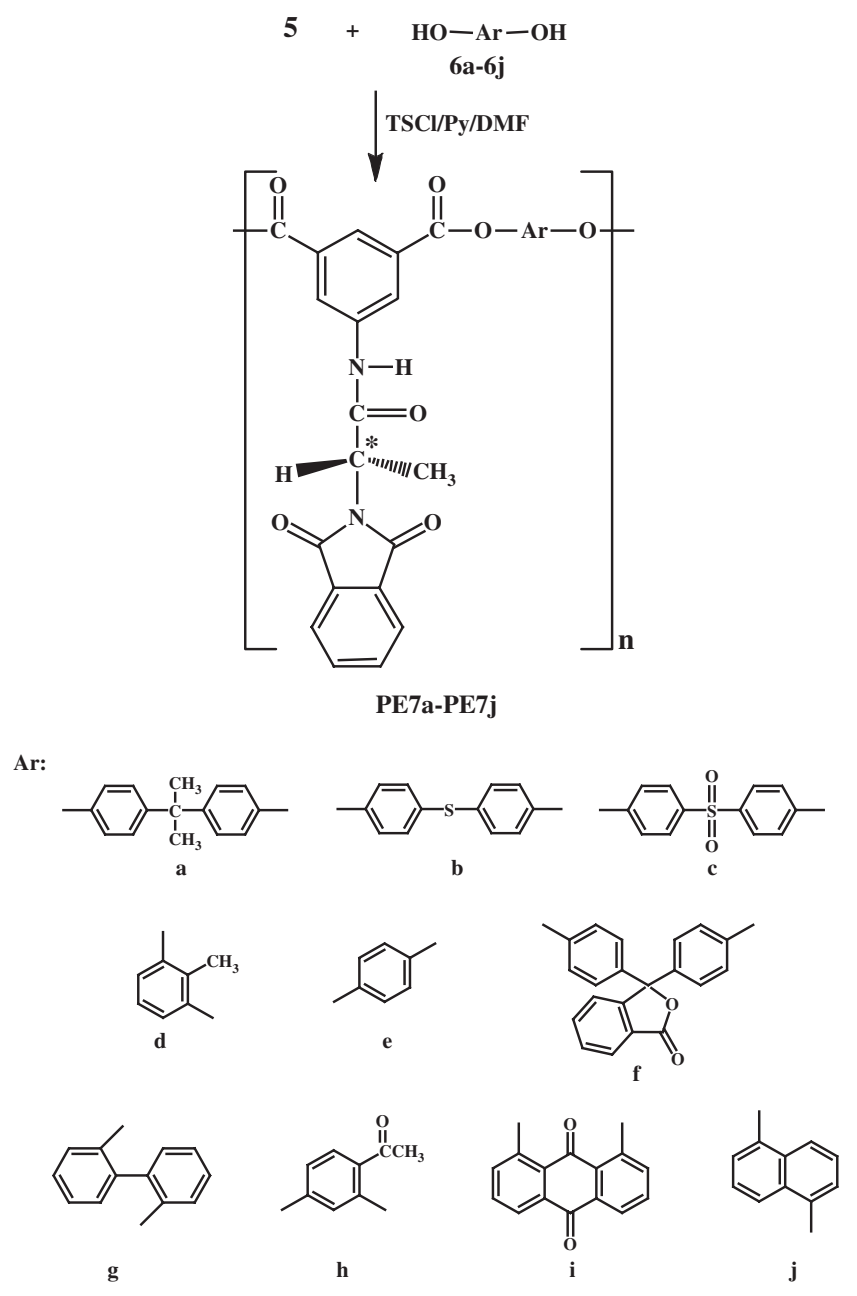

Scheme 2. Polycondensation reaction of monomer 5 with different aromatic diols.

following way: $\mathrm{TsCl}$ was dissolved in Py and after a certain period (aging time) the solution was treated with DMF for $30 \mathrm{~min}$. The reaction mixture was added to a solution of diacid 5 in Py. After a $30 \mathrm{~min}$. a solution of diol in Py was added and the whole solution was maintained at room temperature and elevated temperature for a period of time. Polycondensation
Table I. The optimum conditions for the preparation of PEs (methods I and II)

\begin{tabular}{ccc}
\hline \multicolumn{3}{c}{ Optimum Condition } \\
\hline Method & I & II \\
TsCl/Diacid (mol/mol) & 5.0 & 5.0 \\
Py/Diacid (mol/mol) & 29.5 & 29.5 \\
DMF (mmol) & 0.64 & 0.64 \\
Aging Time (min) & 30 & 30 \\
Addition Time of Diol & $30 \mathrm{~min}$ & $1.5 \mathrm{~h}$ \\
Reaction Time (h) & 5.0 & 2.5 \\
\hline
\end{tabular}

was carried out by varying the aging time of the initial reaction of $\mathrm{TsCl}$ and $\mathrm{Py}$, the molar ratio of $\mathrm{DMF}$ to diacid, the reaction time and reaction temperature. All of these parameters has effect on the polymer chain growth. The main differences between the method I and II is the addition of diol to the activated diacid. In method $\mathbf{I}$ diol was added to the activated diacid after $30 \mathrm{~min}$. of activation at room temperature, while in method II the diol was added after $30 \mathrm{~min}$. at room temperature followed by $1 \mathrm{~h}$ at $120^{\circ} \mathrm{C}$ to effect a clear solution. The optimum conditions for the preparation of PEs are summerized in Table I. We obtained comparable yields and better viscosities of PEs 7a-7j from method II. This finding indicates that when diacid is activated for longer time and higher temperature longer chain growth will occur. The reaction yields and some physical data of these PEs are listed in Tables II and III.

The inherent viscosities of the resulting polymers under optimized condition were in the range of 0.21$0.81 \mathrm{dL} / \mathrm{g}$ and the yields were $70-97 \%$. All of the PEs are optically active. It is interesting to mention that the structure of diols show great effect on the inherent viscosities of the resulting PEs. The highest inherent viscosity was obtained with bisphenol A which could be due to the electron releasing effect of isopropyl group which make the diol more reactive. For other diols lower inherent viscosities were obtained which could be due to both electron-withdrawing as well as steric (also rigidity) effects. Diols $6 \mathrm{~b}, 6 \mathrm{c}, 6 \mathrm{~h}$ and $6 \mathrm{i}$ may exert electron-withdrawing effect, while diols $6 \mathrm{~d}, 6 \mathrm{e}$, $6 \mathrm{f}, 6 \mathrm{~g}$ and $6 \mathrm{j}$ may have steric and rigidity effects.

\section{Polymer characterization}

The introduction of amino acid moiety into synthetic polymers is of attention because these combinations generate new nonbiological polymers with biomimetic structures and properties and consequently have many potential uses, including controlled drug release systems, optical resolution, biologically active and degradable materials. ${ }^{15-17}$

In this investigation, the novel PEs were prepared from an optically active monomer $\mathbf{5}$ using L-alanine 
Table II. Synthesis and some physical properties of PE7a-PE7j prepared by method I

\begin{tabular}{ccccccc}
\hline & \multicolumn{6}{c}{ Polymer } \\
\cline { 2 - 7 } diol & Polymer & $\begin{array}{c}\text { Yield } \\
(\%)\end{array}$ & $\begin{array}{c}\eta_{\text {inh }} \\
(\mathrm{dL} / \mathrm{g})^{\mathrm{a}}\end{array}$ & {$[\alpha]_{N a, 589}^{25, b}$} & {$[\alpha]_{H g}^{25, b, c}$} & {$[\alpha]_{H g, 365}^{25, b, d}$} \\
\hline 6a & PE7aI & 86 & 0.58 & -18.9 & +47.6 & +43.6 \\
6b & PE7bI & 71 & 0.45 & -31.5 & +28.0 & +21.7 \\
6c & PE7cI & 75 & 0.42 & -34.2 & +36.4 & +53.28 \\
6d & PE7dI & 97 & 0.29 & -18.1 & +35.2 & +23.0 \\
6e & PE7eI & 93 & 0.36 & -44.2 & +33.8 & +73.2 \\
6f & PE7fI & 82 & 0.41 & -15.4 & +19.4 & +51.1 \\
6g & PE7gI & 70 & 0.38 & -22.1 & +29.3 & +21.7 \\
6h & PE7hI & 78 & 0.33 & -26.1 & +46.6 & +89.2 \\
6i & PE7iI & 83 & 0.26 & -23.0 & +46.1 & +34.2 \\
6j & PE7jI & 82 & 0.31 & -13.9 & +41.6 & +90.0 \\
\hline
\end{tabular}

${ }^{\mathrm{a}}$ Measured at a concentration of $0.5 \mathrm{~g} / \mathrm{dL}$ in DMF at $25^{\circ} \mathrm{C}$. ${ }^{b}$ Measured at a concentration of $0.5 \mathrm{~g} / \mathrm{dL}$ in DMF at $25^{\circ} \mathrm{C}$. ${ }^{\mathrm{c}}$ Were measured without filter. ${ }^{\mathrm{d}}$ Were measured by the use of filter of $365 \mathrm{~nm}$.

Table III. Synthesis and some physical properties of PE7a-PE7j prepared by method II

\begin{tabular}{ccccccc}
\hline & \multicolumn{6}{c}{ Polymer } \\
\cline { 2 - 7 } diol & Polymer & $\begin{array}{c}\text { Yield } \\
(\%)\end{array}$ & $\begin{array}{c}\eta_{\text {inh }} \\
(\mathrm{dL} / \mathrm{g})^{\mathrm{a}}\end{array}$ & {$[\alpha]_{N a, 589}^{25, b}$} & {$[\alpha]_{H g}^{25, b, c}$} & {$[\alpha]_{H g, 365}^{25, b, d}$} \\
\hline 6a & PE7aII & 82 & 0.81 & -19.2 & +38.7 & +58.9 \\
6b & PE7bII & 92 & 0.48 & -29.8 & +28.4 & +52.1 \\
6c & PE7cII & 91 & 0.51 & -38.2 & +56.2 & 62.1 \\
6d & PE7dII & 78 & 0.21 & -17.7 & +38.1 & +54.1 \\
6e & PE7eII & 87 & 0.45 & -25.0 & +38.4 & +76.0 \\
6f & PE7fII & 81 & 0.48 & -14.7 & +22.1 & +48.5 \\
6g & PE7gII & 86 & 0.26 & -20.2 & +31.4 & +32.9 \\
6h & PE7hII & 85 & 0.38 & -24.1 & +42.4 & +91.2 \\
6i & PE7iII & 87 & 0.22 & -25.1 & +48.6 & +41.9 \\
6j & PE7jII & 82 & 0.33 & -18.9 & +58.2 & +101.2 \\
\hline
\end{tabular}

${ }^{a}$ Measured at a concentration of $0.5 \mathrm{~g} / \mathrm{dL}$ in DMF at $25^{\circ} \mathrm{C}$. ${ }^{b}$ Measured at a concentration of $0.5 \mathrm{~g} / \mathrm{dL}$ in DMF at $25^{\circ} \mathrm{C}$. ${ }^{\mathrm{c}}$ Were measured without filter. ${ }^{\mathrm{d}}$ Were measured by the use of filter of $365 \mathrm{~nm}$.

as amino acid which has a carbon chiral center. It is interesting to mention that, the incorporation of Lalanine not only make the resulting PEs optically active, but also gave polymers with improved solubility. The resulting polymers show optical rotation, therefore are optically active. The formation of PEs was confirmed by FT-IR spectroscopy analysis. As an example, the FT-IR spectrum of PE7f (Figure 3) was showed. FT-IR spectra of all polymers show the characteristic absorption peaks for the imide ring, and ester and amide at 1777, 1746, 1715, $1637 \mathrm{~cm}^{-1}$ respectively due to the symmetrical and asymmetrical carbonyl stretching vibrations. Band of amide $\mathrm{N}-\mathrm{H}$ group appeared around $3413 \mathrm{~cm}^{-1}$. All of them exhib-

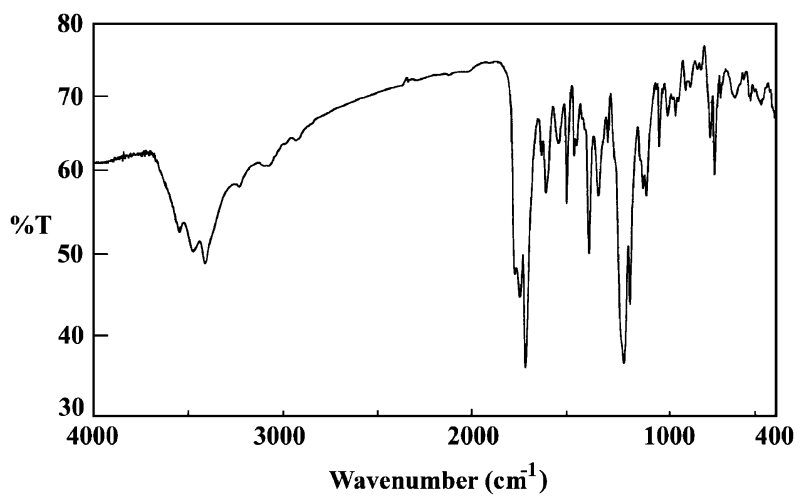

Figure 3. FT-IR spectrum of PE7f.

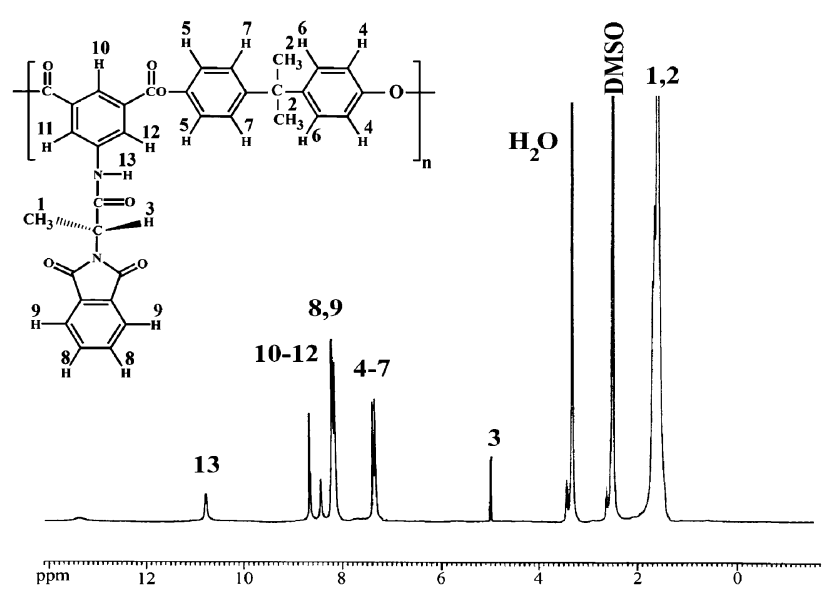

Figure 4. ${ }^{1} \mathrm{H}-\mathrm{NMR}(500 \mathrm{MHz})$ spectrum of PE7a.

ited strong absorptions around $1384 \mathrm{~cm}^{-1}$ and $711-$ $747 \mathrm{~cm}^{-1}$ that show the presence of the imide heterocycle ring in these polymers.

The ${ }^{1} \mathrm{H}$ NMR spectra $(500 \mathrm{MHz})$ of PE7a and PE7b are shown in Figures 4 and 5. In the ${ }^{1} \mathrm{H}$ NMR spectra of these two polymers, appearance of the N$\mathrm{H}$ proton of amide groups around $10.43 \mathrm{ppm}$ point to amide group in the polymer's chain. The absorption of aromatic protons appeared at a range of 7.20$8.68 \mathrm{ppm}$. The proton of the chiral center appeared at $4.97 \mathrm{ppm}$. The absorption of the $\mathrm{CH}_{3}$ protons group of L-alanine appeared at $1.61 \mathrm{ppm}$. In the spectrum of PE7a $\mathrm{CH}_{3}$ protons of bisphenol A appeared at $1.61 \mathrm{ppm}$ which overlapped with $\mathrm{CH}_{3}$ protons of Lalanine group.

The solubility of PEs was tested quantitatively in various solvents are listed in Table IV. All of the PEs are soluble in organic solvents such as DMF, DMAC, dimethyl sulfoxide, $N$-methyl-2-pyrrolidone, Py and in $\mathrm{H}_{2} \mathrm{SO}_{4}$ at room temperature, and are insoluble in solvents such as chloroform, methylene chloride, methanol, ethanol and water. The incorporation of the pendent alaninephthalimide in the side chain PEs enhanced their solubility in polar solvents. 


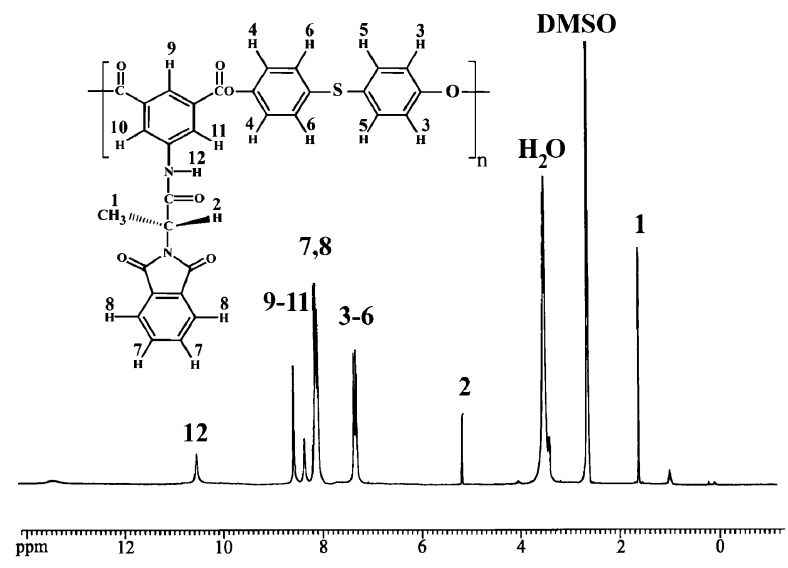

Figure 5. ${ }^{1} \mathrm{H}-\mathrm{NMR}(500 \mathrm{MHz})$ spectrum of PE7b.

\section{Thermal properties}

The thermal stability of polymers was studied by TGA/DTG under a nitrogen atmosphere. Figure 6 presents typical TGA thermograms of PE7aII and PE7cII. The 5 and $10 \%$ weight loss $\left(\mathrm{T}_{5}\right.$ and $\left.\mathrm{T}_{10}\right)$ of the polymers and residue at $600{ }^{\circ} \mathrm{C}$ (char yield) for these polymers are summarized in Table V. The polymers are thermally stable up to above $320^{\circ} \mathrm{C}$ as indicated by the weight loss in TGA thermograms. The initial decomposition temperatures of these polymers are 372 and $320^{\circ} \mathrm{C}$, respectively. PE7aII showed higher thermal stability than PE7cII. This could explain that higher inherent viscosity resulting from PE7aII could be responsible for its higher thermal stability. Upon evaluating the chemical structures of the pendent groups, it is seen that the introduction of phthalimide side group along the polymers backbone improved their thermal stability compared with other PEs which were reported earlier. ${ }^{23-26}$ The DSC analyses for PE7aII and PE7cII show $\mathrm{T}_{\mathrm{g}}$ around 131 and $157^{\circ} \mathrm{C}$, respectively.

\section{CONCLUSION}

A series of new optically active aliphatic-aromatic

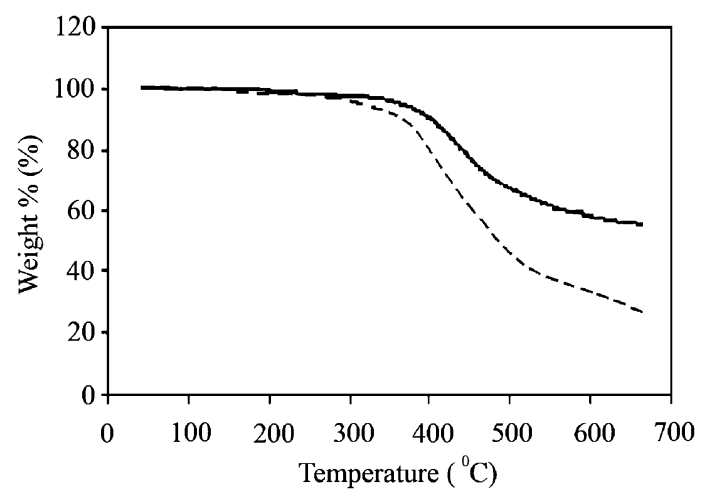

Figure 6. TGA of (-) PE7aII and (- -) PE7cII at a heating rate of $10^{\circ} \mathrm{C} / \mathrm{min}$ under a nitrogen atmosphere.

Table V. Thermal Properties of PE7aII and PE7cII

\begin{tabular}{lcccc}
\hline \multirow{2}{*}{ Polymer } & \multicolumn{2}{c}{$\begin{array}{c}\text { Decomposition Temperature } \\
\left({ }^{\circ} \mathrm{C}\right)\end{array}$} & $\begin{array}{c}\text { Char Yield } \\
(\%)^{\mathrm{c}}\end{array}$ & $\mathrm{T}_{\mathrm{g}}{ }^{\mathrm{d}}$ \\
\cline { 2 - 3 } & $\mathrm{T}_{5}{ }^{\mathrm{a}}$ & $\mathrm{T}_{10}{ }^{\mathrm{b}}$ & & \\
\hline PE7aII & 372 & 400 & 58 & 131 \\
PE7cII & 320 & 372 & 33 & 157 \\
\hline
\end{tabular}

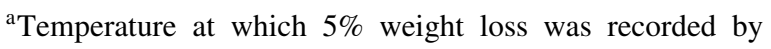
TGA at a heating rate of $10^{\circ} \mathrm{C} / \mathrm{min}$ in nitrogen atmosphere. ${ }^{\mathrm{b}}$ Temperature at which $10 \%$ weight loss was recorded by TGA at a heating rate of $10^{\circ} \mathrm{C} / \mathrm{min}$ in nitrogen atmosphere. ${ }^{c}$ Percentage weight of material left undecomposed after TGA analysis at maximum temperature $600^{\circ} \mathrm{C}$ in nitrogen atmosphere. ${ }^{\mathrm{d}}$ Glass transition temperature was recorded at a heating rate of $20^{\circ} \mathrm{C} / \mathrm{min}$ in a nitrogen atmosphere.

PEs having phthalimide, amide and L-alanine moieties were synthesized by two different methods. Direct polycondensation was carried out by reaction of phthalimide containing diacid and aromatic diols using $\mathrm{TsCl} / \mathrm{DMF} / \mathrm{Py}$ as condensing agent. The polycondenstation leads to the formation of polymers having inherent viscosity ranging from $0.21-0.81 \mathrm{dL} / \mathrm{g}$. The resulting PEs are thermally stable and are readily soluble in common organic solvents. Since these

Table IV. Solubility of PE7a-PE7 $\mathbf{j}^{\text {a }}$

\begin{tabular}{ccccccccccc}
\hline Solvent & PE7a & PE7b & PE7c & PE7d & PE7e & PE7f & PE7g & PE7h & PE7i & PE7j \\
\hline DMAc & + & + & + & + & + & + & + & + & + & + \\
DMF & + & + & + & + & + & + & + & + & + & + \\
NMP & + & + & + & + & + & + & + & + & + & + \\
DMSO & + & + & + & + & + & + & + & + & + & + \\
$\mathrm{Py}$ & + & + & + & + & + & + & + & + & + & + \\
$\mathrm{H}_{2} \mathrm{SO}_{4}$ & + & + & + & + & + & + & + & + & + & + \\
$\mathrm{MeOH}$ & - & - & - & - & - & - & - & - & - & - \\
$\mathrm{EtOH}$ & - & - & - & - & - & - & - & - & - & - \\
$\mathrm{CHCl}_{3}$ & - & - & - & - & - & - & - & - & - & - \\
$\mathrm{CH}_{2} \mathrm{Cl}_{2}$ & - & - & - & - & - & - & - & - & - & - \\
$\mathrm{H}_{2} \mathrm{O}$ & - & - & - & - & - & - & - & - & - & - \\
\hline
\end{tabular}

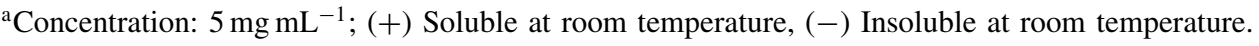


PEs are soluble in many organic solvents, they can be used for film forming and coating materials.

Acknowledgment. We wish to express our gratitude to the Research Affairs Division Isfahan University of Technology (IUT), for financial support. Further financial support from Center of Excellency in Sensors and Green Chemistry Research (IUT) is gratefully acknowledged.

\section{REFERENCES}

1. J. K. Fink, in "Reactive Polymers Fundamentals and Applications," New York, Plastics Design Library, 2005.

2. H. Han and P. K. Bhowraik, Prog. Polym. Sci., 22, 1431 (1997).

3. J. Y. Jadhav and S. W. Kantor, in "High Performance Polymers and Composites" J. I. Kroschwitz, Ed., New York, Wiley, 1991.

4. Y. Chen, Y. Yang, J. Su, L. Tan, and Y. Wang, React. Funct. Polym., 67, 396 (2007).

5. E. Bucio, J. W. Fitch, S. R. Venumbaka, E. Patrick, and P. E. Cassidy, Polymer, 46, 3971 (2005).

6. P. E. Cassidy, in "Thermally stable polymers" New York, Marcel Dekker, 1980.

7. B. Tamami, H. Yeganeh, and G. A. Kohmareh, Eur. Polym. J., 40, 1651 (2004).

8. T. Vlad-Bubulac, C. Hamciuc, O. Petreus, and M. Bruma, Polym. Adv. Technol., 17, 647 (2006).

9. H. J. Jeong, M. A. Kakimoto, and Y. Imai, J. Polym. Sci., Polym. Chem., 32, 1057 (1994).

10. D. J. Liaw and P. S. Chen, J. Polym. Sci., Polym. Chem., 34,
885 (1996).

11. F. Higashi and T. Mashimo, J. Polym. Sci., Part A: Polym. Chem., 24, 1697 (1986).

12. F. Higashi and T. Mashimo, J. Polym. Sci., Polym. Chem. Ed., 23, 2999 (1985).

13. F. Higashi and A. Tobe, Macromol. Chem. Phys., 202, 745 (2001).

14. F. Higashi, R. Hayashi, and T. Yamazaki, J. Appl. Polym. Sci., 86, 2607 (2002).

15. F. Sanda and T. Endo, Macromol. Chem. Phys., 200, 2651 (1999).

16. R. Katsarava, Macromol. Symp., 199, 419 (2003).

17. T. W. Baughman and K. B. Wagener, Adv. Polym. Sci., 176, 1 (2005).

18. Y. Okamoto, Prog. Polym. Sci., 25, 159 (2000).

19. G. Wulff, Angew. Chem., Int. Engl. Ed., 28, 21 (1989).

20. E. Abdul Rahim, F. Sanda, and T. Masuda, J. Polym. Sci., Part A: Polym. Chem., 44, 810 (2006).

21. S. Mallakpour and E. Kowsari, Polym. Eng. Sci., 46, 558 (2006).

22. S. Mallakpour and M. Kolahdoozan, e-polymer, no. 020 (2006).

23. S. Mallakpour and M. H. Shahmohammadi, Iranian Polym. J., 14 (11), 974 (2005).

24. S. Mallakpour and E. Kowsari, J. Appl. Polym. Sci., 101, 455 (2006).

25. S. Mallakpour and M. Kolahdoozan, Iranian Polym. J., 15, 307 (2006).

26. S. Mallakpour and E. Kowsari, Polym. Bull., 55, 51 (2005).

27. J. R. Casimir, G. Guichard, and J. P. Briand, J. Org. Chem., 67, 3764 (2002).

28. A. K. Bose, F. Greer, and C. C. Price, J. Org. Chem., 23, 1335 (1958). 